\title{
Thomas Bernhard "servido" por Joaquim Benite
}

\author{
Miguel-Pedro Quadrio
}

O teatro sempre foi politico, uma vez que sempre se referiu à polis, à cidade. Nesse sentido, o papel politico do teatro é uma condição da sua existência. É evidente que quando digo que o teatro é político não estou a dizer que ele deva ser alinhado com uma ideologia ou uma interpretação global do mundo. Quero dizer sim que se trata de um teatro interessado na História, na vida do dia a dia, e interessado nos problemas que a Humanidade enfrenta.

0 fazedor de teatro, de Thomas Bernhard, enc. Joaquim Benite, Companhia de Teatro

de Almada, 2004 (Morais e Castro) fot. Humberto Sousa.

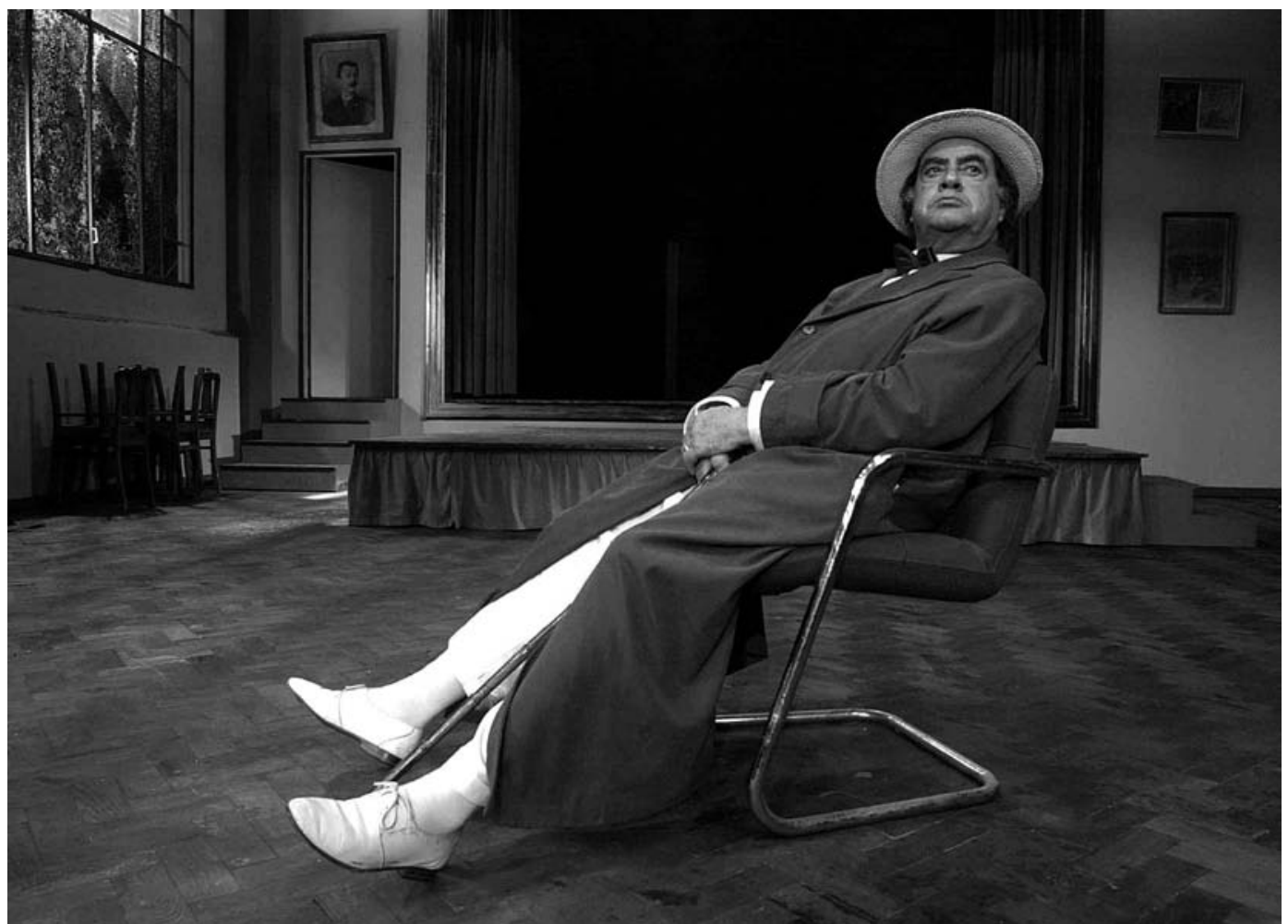

A 29 de Janeiro de 2004 estreou-se, no Teatro Municipa de Almada, a encenação de Joaquim Benite d'O fazedor de teatro (Der Theatermacher), de Thomas Bernhard (19311989). Este é o facto. Quanto à memória, o espectáculo permanecerá na de quem o fez, a ele assistiu e deficitariamente - no que sobre ele se escreveu; quanto ao texto, os ensaios reunidos no vigésimo número do caderno Textos de Almada poderão ajudar quem queira situar esta peça de 1984 no universo dramático do dramaturgo austríaco. Ora, na ocasião em que a Associação Portuguesa de Críticos de Teatro entrega a Menção Especia com que distinguiu esta produção da Companhia de Teatro de Almada - e cabendo-me, como membro do Júri que unanimemente a votou, uma justificação pública dessa escolha - não me parece particularmente interessante (nem produtivo) voltar a reiterar apenas uma argumentação que se cinja à qualidade estética do espectáculo. Pelo contrário, e dado que sobre ele escrevi pelo menos duas vezes, queria clarificar hoje um outro aspecto que, dada a escassez de espaço - ou a falta de arte -, tentei transmitir no Diário de notícias em formulações ambíguas, porque (aparentemente) generalistas ou excessivamente afectivas: na crítica publicada durante a carreira do espectáculo, considerei-o "uma das mais deslumbrantes e poderosas criações da Companhia de Teatro de Almada" (Quadrio 2004a) e, no balanço do ano teatral, classifiquei-o como 
a "melhor direcção de sempre" de Joaquim Benite (distinguindo ainda Morais e Castro, que interpretou o protagonista, como o melhor desempenho masculino do ano que então findava: cf. Quadrio 2004b). Com estas duas variações do mesmo juizo superlativo quis anotar afinal que, a par da inegável distinção performativa já referida, esta encenação apresentava uma iniludivel marca ética - ou política, se entendermos a noção no seu sentido mais nobre - que não só a tornava exemplo significativo do "desabrido rigor" com que Joaquim Benite vem programando e trabalhando o texto teatral, como Ihe conferia um valor metonímico relativamente à atitude da Companhia Teatral de Almada face à comunidade em que hoje se insere. Proponho três argumentos para a identificação dessa dimensão do fazer teatral e da sua correlata eficácia.

Em primeiro lugar, Joaquim Benite escolheu "um texto que fala". Thomas Bernhard compôs 0 fazedor de teatro como uma redução absurda e bizarra do carácter tautológico que caracterizou a reflexão estética e a prática artística do século XX. Neste texto dramático - escrevi-o na crítica - tudo é claro e preciso: o contexto (em tournée pela Áustria, Bruscon, um actor falhado, e a sua trupe, parodicamente resumida à mulher e aos filhos Ferruccio e Sara, chegam a um lugarejo insignificante, Utzbach, para mais uma récita d'A roda da História, uma comédia da autoria do próprio Bruscon); o tempo, o espaço e as personagens (a acção decorre entre as três e as sete e meia da tarde, na sala da estalagem "Veado Negro", onde se prevê que a representação venha a ter lugar, surgindo, para além dos Bruscon, as figuras quase mudas dos donos da hospedaria e da respectiva filha); e um enredo desenvolvido em quatro cenas, que gira em torna da remontagem da peça (cf. Quadrio 2004a). No entanto, como bem assinala José A. Palma Caetano, tradutor da versão usada por Joaquim Benite, esta é "uma peça em que propriamente não há acção, não há conflito e não há verdadeiramente uma história" (2004: 5). Aparentemente, estas duas caracterizações parecem contradizer-se. Conciliam-se, todavia, se nos lembrarmos que Bernhard se posicionou face a esta intriga "inactiva" como um "Beckett musical", ou seja, à semelhança do efeito que a tragédia absurda da vida e do homem provocara no teatro do irlandês, silenciando-o até aos "actos sem palavras", no deste austríaco metamorfoseou-o num jogo complexo de longa duração, que cruelmente expõe a ilusão da "quantidade" das palavras ditas (tão valorizada no quadro das democracias ocidentais) e que, recorrendo à repetição das intervenções em séries semelhantes mas nunca idênticas, sinaliza o vazio significativo que pode resultar da capacidade humana para produzir infinitos enunciados distintos. Note-se, ainda, que a avassaladora solidão que aflige as descarnadas personagens de Beckett, muitas vezes restringidas a um inquietante imobilismo, se reflecte com igual intensidade nas figuras agitadas concebidas por Bernhard e na sua tendência para se diluírem em infindáveis e rebarbativos (quase) monólogos.
Além de escolher um texto que fala, Joaquim Benite deixou que "o texto falasse". A discrição com que o encenador quis assinalar a sua "presença ausente" tornou-se óbvia na selecção da tradução e na concepção plástica do espectáculo. Ao utilizar uma versão "que tende a ficar 'rente ao texto' de partida" - conclusão de Alexandra Lopes (2004: 114) que me parece resumir certeiramente a tendência conservadora da tradução utilizada - Benite assumiu claramente o risco de confrontar o público português com uma profusão de referências contextuais que pouco ou nada Ihe diriam. A apresentação de Bruscon como um "actor nacional" que se vê forçado a cumprir uma itinerância por lugares e em espaços insignificantes, as constantes alusões à comédia que se propõe representar (uma "roda da História" onde, em curto-circuito constante, se glosa o recente e pouco edificante percurso da Áustria) ou um cómico de linguagem que frequentemente se socorre da culinária local (as discussões estéticas podem desembocar ou ter origem em minuciosas divagações sobre o modo de preparar "sopa de massa frita" ou um qualquer outro prato típico) são algumas das subtilezas irónicas que, ao serem mantidas e até realçadas pela dramaturgia, fariam prever uma menor comunicabilidade do espectáculo. Também os figurinos "localistas" de Sónia Benite e o minucioso espaço de representação concebido pelo cenógrafo francês Jean-Guy Lecat - onde se reconstituiu um degradado salão de festas, similar aos que se encontravam nas sociedades recreativas da primeira metade do século XX - se situavam na mesma ambiguidade interpretativa, ou seja, ao mesmo tempo que materializaram com obsessivo e indiscutivel rigor o contexto d'O fazedor de teatro, acentuaram ainda mais a sua intradutibilidade cultural. E será - acrescentaria eu - que o obsessivo teatro de Bernhard se poderá fazer de uma outra maneira?

Ora, além de ter escolhido um texto que fala e de o deixar falar, Joaquim Benite criou as condições para que "o 'seu' público o ouvisse". 0 encenador encontrou no próprio texto a estratégia para o integrar na cultura de chegada. 0 principal achado concretizou-se na surpreendente acomodação à realidade nacional da oposição irónica entre o "actor nacional" Bruscon e o Bruscon, que, dadas as circunstâncias, se vê obrigado a uma humilhante presença em Utzbach. Quando Benite recorreu a Morais e Castro, um actor que vem devendo a sua fama crescente a uma omnipresença televisiva, encontrou nessa visibilidade a condição portuguesa de um "actor nacional". Programar a sua actuação para o palco de um grupo de teatro independente (neste caso, a Companhia de Teatro de Almada) poderia sugerir graciosamente a invisibilidade da insignificante Utzbach, dado o desequilíbrio de meios e de audiências entre um colectivo teatral e um programa cómico transmitido em prime-time. Além desta saborosa provocação das expectativas do público, o convite permitiu também dois efeitos igualmente relevantes: (a) demonstrar uma criteriosa capacidade para constituir um elenco: não só Morais e Castro é dos poucos actores portugueses que se adequariam 
0 fazedor de teatro de Thomas Bernhard, enc. Joaquim Benite,

Companhia de Teatro de Almada, 2004 (Morais e Castro), fot. Humberto Sousa.

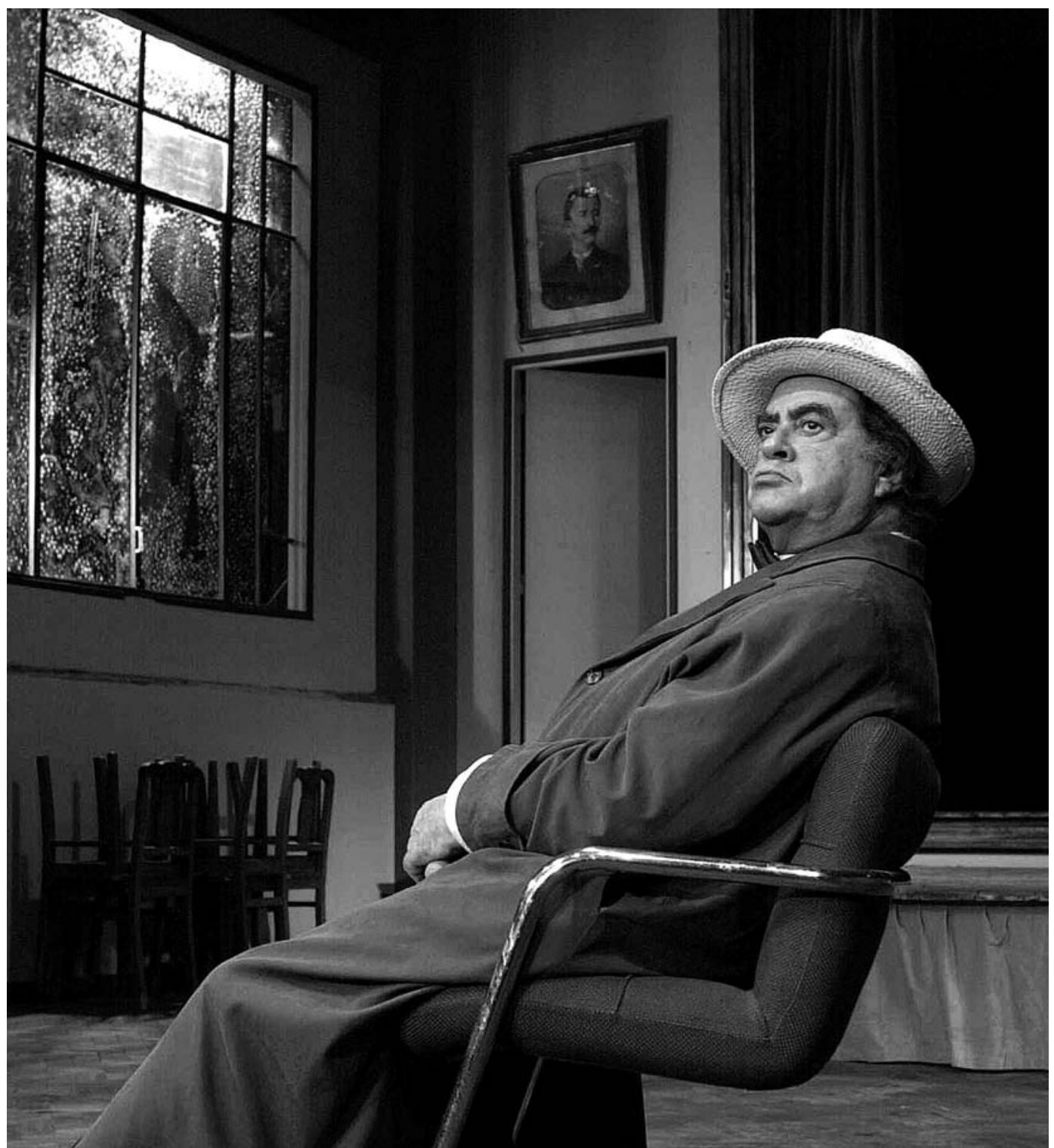

à desmesurada personagem de Bruscon - a sua antológica interpretação muito ficou a dever ao modo como Benite geriu rigorosamente a prolixidade "deste" Bruscon, o seu movimento e presença em palco, a sua capacidade para contrastar e variar registos - como se explorou a sua imensa e peculiar potencialidade expressiva em perfeita articulação com as valências dos restantes intervenientes, desenhados como se fossem títeres de uma tão hilariante, quanto descoroçoada pantomina (Francisco Costa foi um estalajadeiro perplexo que suportou os desmandos de Bruscon numa impressiva contracena silenciosa, Teresa Gafeira, sua mulher, uma austríaca "típica", que se desconjuntava como uma marioneta, Miguel Martins um apatetado Ferrucio e Maria Frade uma filha doce e resignada); (b) caucionar uma estratégia eficaz de comunicabilidade: utilizou-se a previsível empatia do público com a actuação de Morais e Castro para suprir eventuais distanciamentos e perplexidades que as indeléveis marcas culturais desta peça poderiam provocar num auditório transversal.

É esta sageza de dar a ver o melhor teatro nas condições ideais para que qualquer tipo de público a ele tenha acesso - esforço não só concretizado na equilibradíssima programação da Companhia de Teatro de Almada, mas que também se tem reflectido na criteriosa selecção dos espectáculos que preenchem a oferta anual do Festival de Teatro de Almada (uma estratégia claramente sancionada pelo número crescente de espectadores que participam na iniciativa) - que transforma o trabalho de Joaquim Benite com a Companhia de Teatro de Almada num dos mais relevantes e inteligentemente comprometidos projectos do nosso panorama teatral.

\section{Referências bibliográficas}

CAETANO, José A. Palma (2004), "A denúncia do absurdo (a propósito de 0 fazedor de teatro)", Textos de Almada, Almada, CTA, n. 20, pp. 3-8.

LOPES, Alexandra (2004), "Os tradutores, esses fazedores de cultura" [recensão à tradução de José A. Palma Caetano de 0 fazedor de teatro, de Thomas Bernhard], Sinais de cena, n. ${ }^{2}$ 2, Lisboa, APCT / CET, Dezembro, pp. 112-114.

QUADRIO, Miguel-Pedro (2004a), "Thomas Bernhard e a boa morte do teatro", Diário de notícias, 17 de Fevereiro.

-- (2004b), "Os espectros do teatro", Diário de notícias, 30 de Dezembro. 